\title{
Homo Sapiens vs. Homo Ludens en Tres Cuentos de Cortázar
}

Ma pbilosopbie consiste à dire que tout est jeu, que l'être est jeu, que l'univers est jeu, que l'idée de Dieu est mal venue, au surplus insupportable, en ce que Dieu qui ne peut être initialement, bors du temp, qu'un jeu, est attelé par la pensée bumaine à la création, et à toutes les implications de la création, qui sont contraires aul jeu.

-..........

Le jets est l'indéfinissable, ce que la pensée ne peut concevoir. (Georges Bataille, Conférence sur le NonSavoir).

El espíritu de juego asoma a lo largo de la obra de Cortázar desde el título mismo de sus libros: Los premios - una travesía de destino incierto reúne a los premiados en un juego de lotería; Rayuela- un juego que en la antigüedad era un laberinto en el cual se empujaba una piedra (el alma) hacia la salida, y que con el cristianismo se simplifica y conviette en el diseño de una basílica: tirando la piedra se busca transportar el alma al cielo, al paraíso, a la corona o la gloria cuyo rectángulo coincide con el altar mayor de la iglesia; 62. Modelo para armar implica su lectura como un juego: un rompecabezas o un mecano. cuyas partes se suministran para que el lector componga con ellas la novela. Una de sus colecciones de cuentos lleva por título, sin más ni más, Final del juego, y en la más reciente edición de sus cuentos completos (Relatos, 1970) Cortázar los ha reordenado en tres partes - Ritos, Juegos, Pasajes. También en sus dos libros de ensayos corretea una actitud deliberadamente lúdica: desde los títulos - La vuelta al día en ochenta mundos y Ultimo rotund - hasta el estilo desalmidonado con que Cor- 
tázar desengomina clisés, gambetea solemnidades y hace que el humor golee a los tortugones de cuello duro. En el ensayo "No hay peor sordo que el que", Cortázar define algunas de las dificultades que hacen trastabillar al escritor rioplatense. "Nosotros" - dice--, "a diferencia del escritor europeo que escribe con armas afiladas colectivamente por siglos de tradición intelectual, estética y literaria, estamos forzados a crearnos una lengua que primero deje atrás a Don Ramiro y otras momias de vendaje hispánico, que vuelva a descubrir el español que dio a Quevedo - Cervantes y que nos dio Martín Fierro y Recuerdos de provincia, que sepa inventar, que sepa abrir la puerta para ir a jugar. ." I La última frase, además de ser parte de una rima en que todo lector argentino reconoce el estribillo de un juego infantil, plantea la literatura como un juego, o, más bien, redefine el juego como una actividad humana cuyo sentido y alcance es el tema de este trabajo.

Desde la aparición del libro de Johan Huizinga, Homo ludens, en 1938, el estudio de los juegos constituye un campo de indagación en el que compiten varias disciplinas. Desde la perspectiva de la psicología ha sido estudiado por Jean Piaget y por Jean Chateau en libros como Le réel et l'imaginaite dans le jeu de l'enfant y Le jeu de l'enfant. Introduction à la pédagogie. $\mathrm{El}$ interés de los psicólogos por el juego parece residir más bien, como anota Roger Caillois, ${ }^{2}$ en la función que éste tendria en la formación de la personalidad del futuro adulto. Desde el punto de vista de los psicólogos "el juego se presenta como una educación - sin fin predeterminado- del cuerpo, el carácter o la inteligencia". ${ }^{3}$ Para los matemáticos, en cambio, el estudio de los juegos ha dado lugar a un nuevo campo de investigación que desde los trabajos de John von Neumann y Oskar Morgenstern conocemos bajo el nombre de "teoría de los juegos". Esta teoría parte de la distinción entre las reglas que estructuran el juego y las varias opciones de los participantes, entre las reglas de base $y$ las reglas de estrategia. Las reglas de base constituyen modelos mecánicos o paradigmas ideales de lo que la gente debe hacer, mientras que las reglas de estrategia son modelos estadísticos de lo que la gente realmente hace. El nivel de reglas de base concierne a

1 La vuelsa al dia en ochenta mundos, México, 1967, p. 100. Para las obras de Cortázar se emplearán las siguientes abreviaturas: VDOM (Vuelta al día en ochenta mundos), UR (Ultimo round), R (Rayuela), FJ (Final del juego), B (Bestiario), AS (Las armas secretas).

2 Roger Caillois, Teoria de los juegos (Barcelona, 1958) p. 161.

s Ibid., pp. 160-161.

* El libro de von Neumann y Morgenstern, Theory of Games and Economic Bebavior (Princeton, 1944), constituye la obra clásica dentro de esta nueva rams de las ciencias. 
la sociología mientras que el nivel de las reglas de estrategia ocupa en especial a la psicología. La teoria de los juegos intenta formular en términos matemáticos las relaciones entre los dos tipos de reglas. Uno de los conceptos centrales de esta teoría es la noción de estrategia, que consiste en un plan completo donde se especifican la conducta de los jugadores para todas las circunstancias y contextos posibles que cobran alguna importancia en el curso del juego. ${ }^{5} \mathrm{La}$ teoría de los juegos ha encontrado provechosa aplicación en la resolución de problemas sociologicos, económicos y políticos.

Los estudios de Huizinga y de Roger Caillois representan aproximaciones menos especializadas y por lo mismo más interesadas en el juego como actividad humana, sin aplicación inmediata a una ciencia o disciplina. Constituyen algo así como la respuesta de las humanidades al interrogante de los juegos. El libro de Caillois - Théorie des jeux- se propone hilar fino donde Huizinga generaliza en exceso. "Homo ludens" -dice Caillois del libro de Huizinga- "es discutible en la mayoría de sus afirmaciones, aunque por su propio carácter abre caminos extremadamente fecundos a la investigación y al pensamiento. En todo caso cabe a Huizinga el perdurable honor de haber analizado magistralmente varios de los caracteres fundamentales del juego y de haber demostrado la importancia de su papel en el desatrollo mismo de la civilización"." Caillois intenta una clasificación más rigurosa y completa de los juegos, incluyendo las apuestas y los juegos de azar, ignorados por Huizinga. Su libro es una especie de systema naturae de los juegos $\mathrm{y}$, en muchos casos, sus conclusiones sólo confirman las alcanzadas por Huizinga.

Las definiciones de juego de Huizinga y Caillois coinciden en situar su esfera de actividad fuera de los límites de nuestro acontecer histórico. Para Huizinga el juego "es una actividad libre ejecutada 'como si' y situada fuera de la vida diaria pero, al mismo tiempo, capaz de absorber por completo al jugador. Es una actividad que no ofrece interés material alguno o utilidad de ningún tipo. Se ejecuta dentro de un determinado tiempo y un determinado espacio según un orden y reglas fijadas de antemano". ${ }^{7} \mathrm{La}$ definición de juego de Caillois ordena los rasgos anotados por Huizinga en seis características fundamentales: libertad, definición de límites, inseguridad en los resultados, improductividad,

- Véase Gams Theory in the Bebavioral Sciences de Ira R. Buchler y Hugo G. Nutini (1969). También: Game Theory; a Nontechnical Introduction (1970) de Morton D. Davis y Introduction to the Theory of Games de Ewald Burget (1959).

- Roger Caillois, op. cit., p. 11.

7 Johan Huizinga, Homo ludens (Buenos Aires 1968), p 29. 
reglamentación y carácter ficticio. En los dos últimos rubros, Caillois afirma que "el juego es una actividad sometida a convenciones que suspenden las leyes ordinarias y que instauran momentáneamente una legislación nueva, que es la única que cuenta, y que es una actividad ficticia en el sentido de que está acompañada de una conciencia específica de realidad segunda o de franca irrealidad en relación a la vida corriente".8 En ambas definiciones el juego es una actividad desarticulada de la vida corriente y funda un orden que suspende o cancela el orden histórico. Las dos ven en el juego una entidad autónoma y uno de los términos de una dicotomía donde juego implica gratuidad, y vida corriente, en cambio, seriedad. Esta polarización entre vida y juego está reforzada por el vocabulario que tanto Huizinga como Caillois emplean para distinguir la una del otro. A la seriedad de la vida se contrapone el carácter lúdico del juego; a la utilidad y fecundidad de la primera, lo gratuito y estéril del segundo; la vida corriente está asociada con el trabajo y la actividad científica y constituye la realidad; el juego, en cambio, está asociado al ocio y la literatura y habita un mundo irreal. Un dualismo tan radical deja entrever la falacia que sirve de apoyo a sus precisiones. Postular la irrealidad y gratuidad del juego sin antes definir los límites y el sentido de lo que en la vida corriente se ha adoptado como "realidad" equivale a suponer fundamentos donde quizá no los haya. A tal inconsecuencia responden las objeciones de Jacques Ehrmann: "Nuestra crítica a las definiciones del juego de Huizinga y Caillois" -escribe Ehrmann- "se basa en el hecho de que esas definiciones consideran "la realidad', "lo real', como un componente ya comprobado y dado del problema, como un referente que no necesita discusión, como algo obvio, neutral y objetivo. Huizinga y Caillois definen el juego por oposición, en base o en relación a esa tal realidad... ¿Cómo puede 'la realidad' servir de norma y asi garantizar la normalidad aun antes de haber sido probada y evaluada en sus manifestaciones y. a través de ellas? Porque -huelga decirlo- no hay realidad (ordinaria o extraordinaria) fuera de esas manifestaciones de la cultura que la expresan"." Ehrmann concluye que "en una antropología del juego, el juego no puede definirse aislándolo en base a su relación con una realidad concebida a priori. Definir el juego representa al mismo tiempo y en el mismo movimiento definir la realidad". 10

\footnotetext{
8 Roger Callois, op. cit., pp. 21-22.

- Jacques Ehrmann, "Homo Ludens Revised" en Game, Play, Lisepature, Beacon Press, 1968 (Edited by J. Ehrmann), p. 33.

10 Ibid., p. 35 .
} 
Pero tal cometido va más allá de los propósitos de Huizinga y de Caillois que estudian el juego como una institución aislada, como una actividad humana recluida a un tiempo ahistórico y a un espacio marginal. Huizinga, sin embargo, reconoce que "la cultura humana brota del juego - como juego - $y$ en él se desarrolla". ${ }^{11} \mathrm{Y}$ en otro lugar, casi contradiciendo la orientación general que sigue su libro, afirma: "No se trata para mi, del lugar que al juego corresponda entre las demás manifestaciones de la cultura, sino en qué grado la cultura misma ofrece un carácter de juego". ${ }^{12} \mathrm{Y}$ en las últimas páginas de su estudio, Huizinga admite: "Hemos considerado el juego en su significación cotidiana $y$ hemos procurado evitar la fácil generalización que a todo declara juego. Al final, sin embargo, se nos enfrenta esta concepción y nos obliga a tomar posición frente a ella". ${ }^{33}$ Su respuesta es una cita entresacada de las Leyes donde Platón propone que "Dios es, por naturaleza, digno de la más santa seriedad. Pero el hombre ha sido hecho para ser un juguete de Dios y esto es lo mejor en él. Por eso tiene que vivir de esa manera, jugando los más bellos juegos..." 14 Tal respuesta y lo que agrega en los párrafos finales de su libro, representa un intento de comprensión ontológica del juego. Su interés puramente investigativo cede a un esfuerzo filosófico por entender ya no las manifestaciones convencionalizadas del juego sino al hombre mismo como un ser cuyo "hacer no es más que un jugar". ${ }^{15}$ De esta comprensión del hombre emerge la noción de bomo ludents que Huizinga opone a la de bomo sapiens porque, explica, esta designación "no convenía tanto a nuestra especie como se había creído en un principio ya que, a fin de cuentas, no somos tan razonables como gustaba de creer el siglo XviII en su ingenuo optimismo". 16 Huizinga también reconoce que "el juego es más antiguo que la cultura" 1 ? y que su tealidad "no puede basarse en ninguna conexión de tipo racional". ${ }^{18}$ "La existencia del juego" - concluye- "corrobora constantemente, y en el sentido más alto, el carácter supralógico de nuestra situación en el cosmos... Nosotros jugamos y sabemos que jugamos; somos, por tanto, algo más que meros seres de razón, puesto que el juego es irracional". ${ }^{10}$

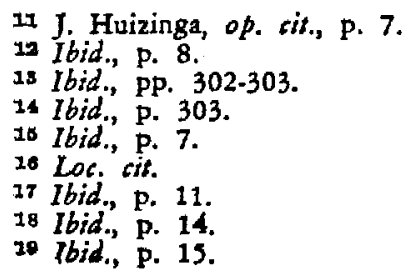


Enfocado el juego como una forma de ser del hombre en el mundo, comenzamos a aproximarnos a una concepción antropológica del juego ya entrevista por Platón y aludida en algún versículo de Proverbios (VIII, 30-32). A esta idea del juego hace referencia Schiller en sus Cartas sobre la education estética del bombre cuando escribe que "el hombre juega solamente cuando es hombre en el sentido cabal de la palabra y es totalmente hombre sólo cuando juega". ${ }^{20}$ También para Nietzsche el mundo todo no es sino un juego y Heidegger creía que "la esencia del Ser es el juego mismo".21 En un estudio mảs reciente, El juego como simbolo del zniverso (Das Spiel als Weltsymbol, 1960) de Eugen Fink, el juego alcanza la más ambiciosa de las definiciones: "Si definimos el juego" - dice Fink- "de la manera acostumbrada contrastándolo con el trabajo, la realidad, la seriedad y la autenticidad, lo guxtaponemos falsamente con otros fenómenos existenciales. El juego es un fenómeno existencial básico, tan primordial y autónomo como la muerte, el amor, el trabajo y la lucha por el poder, pero no está subordinado a estos fenómenos en un propósito común y último. El juego, puede decirse, los confronta a todos - los absorbe representándolos. Jugamos a ser serios, jugamos a la verdad, jugamos a la realidad, jugamos al trabajo y a la lucha, jugamos al amor y a la muerte $-\mathrm{y}$ hasta jugamos a jugar". 22

Si el bomo ludens es una alternativa al bomo sapiens, si la condición del juego es una libertad perdida en el llamado "mundo real" y que el juego rescata y convierte en ruta de retorna hacia el hombre, es comprensible que Cortázar haya definido la poesía -que ya en su ensayo sobre la "Situación de la novela" él mismo describia como "la más honda penetración en el ser de que es capaz el hombre"23 - como juego. Comentando su "poesía permutante" incluida en Ultimo round, dice: "Estos juegos fueron comenzados en Delhi...", y a renglón seguido explica: "Digo juego con la gravedad con que lo dicen los niños. Toda poesía que merezca ese nombre es un juego, y sólo una tradición romántica ya inoperante persistirá en atribuir a una inspiración mal definible y a un privilegio mesiánico del poeta, productos en los que las técnicas y las fatalidades de la mentalidad mágica y lúdica se aplican naturalmente (como lo hace el niño cuando juega) a una ruptura del condicionamiento

\footnotetext{
10 Citado por Kostas Axelos en "Planetary Interlude" incluido en Game, Play, Literature, p. 7.

21 Ibid., P. 8 .

22 Eugen Fink, "The Oasis of Happiness: Toward an ontology of play's incluido en Game, Play, Literature, p. 22.

${ }^{23}$ Julio Cortázar, "Situación de $\mathrm{l}_{\mathrm{a}}$ noevla", Cuadernos Americanos, julioagosto 1950, P. 228.
} 
corriente, a una asimilación o reconquista o descubrimiento de todo lo que está al otro lado de la Gran Costumbre. El poeta no es menos 'importante' visto a la luz de su verdadera actividad (o función, para los que insistan en esa importancia), porque jugar poesía es jugar a pleno, echar hasta el último centavo sobre el tapete para arruinarse o hacer saltar la banca. Nada más riguroso que un juego; los niños respetan las leyes del barrilete o las esquinitas con un ahinco que no ponen en las de la gramática" (UR, 65-66). El juego, pues, como "ruptura del condicionamiento corriente", como "descubrimiento de todo lo que está del otro lado de la Gran Costumbre. Para Cortázar la "Gran Costumbre" es ese mundo codificado y sistematizado de la cultura occidental, un mundo que, según palabras de Oliveira en Rayuela, se define en "la crisis y la quiebra total de la idea clásica del homol sapiens" ( $R, 515)$. Toda la obra de Cortázar es un esfuerzo por trascender ese bomo sapiens, o, como se nos dice a lo largo de Rayuela, por "ir más allá del criterio griego de verdad y error", "más allá de la lógica aristotélica y de las categorías kantianas", más allá de "la gran máscara podrida de occidente", más allá de "la Gran-Infatuación-Idealista-Realista-Espiritualista-Materialista del Occidente, S.R.L.". ¿Para llegar adónde? En Rayuela se menciona el centro del mandala, el cielo de la rayuela, el kibbuts, el. Iggdrassil, la Edad de Oro, el Edén, la Arcadia, el reino milenario, la tierra de Hurqalyã: metáforas-símbolos con las cuales se alude a una realidad inédita cuya puerta todos buscan. Pero, agrega Cortázar, "el bomo sapiens no busca la puerta para ir a jugar, para entrar en el reino milenario, sino solamente para poder cerrarla a su espalda" (R. 433).

Si Rayuela es, como ha explicado. Cortázar, "Ia filosofia de sus cuentos, una indagación sobre lo que determinó a lo largo de muchos años su materia o su impulso" (VDOM, 25), algunos de sus cuentos representan verdaderas soluciones lúdicas a esos mismos interrogantes planteados en la novela. Lúdicas en el sentido de que los personajes y las situaciones de sus relatos actúan y se organizan como en un juego en el cual el jugador se desdobla, según la observación de Eugen Fink, "en el hombre teal que juega y el hombre creado por el papel dentro del juego", solamente que ahora el hombre creado por el juego emerge como el hombre real y aquél que definíamos como "real" se redefine como un papel dentro de un juego indeseado en el que más que jugar nos juegan. El propio Cortázar ha explicado esa "constante lúdica" de algunos de sus cuentos:

Siempre seré como un niño para tantas cosas, pero uno de esos niños que desde el comienzo llevan consigo al adulto, de manera 
que cuando el monstruito llega verdaderamente a adulto ocurre que a su vez éste lleva consigo al niño, y nel mezzo del camin se da una coexistencia pocas veces pacífica de por lo menos dos aperturas al mundo.

Esto puede entenderse metafóricamente pero apunta en todo caso a un temperamento que no ha renunciado a la visión pueril como precio de la visión adulta, y esa yuxtaposición que hace al poeta y quizá al criminal, y también al cronopio y al humorista (cuestión de dosis diferentes, de acentuación aguda o esdrújula, de elecciones: ahora juego, ahora mato) se manifiesta en el sentimiento de no estar del todo en cualquiera de las estructuras, de las telas que arma la vida y en las que somos a la vez araña y mosca.

Esta especie de constante lúdica explica, si no justifica, mucho de lo que he escrito o he vivido... Me aburte atgumentar a posteriori que a lo largo de esa dialéctica mágica un hombre-niño está luchando por rematar el juego de vida: que si, que no, que en ésta está. Porque un juego, bien mirado, ¿no es un proceso que parte de una descolocación para llegar a una colocación, a un emplazamiento - gol, jaque mate, piedra libre? ¿No es el cumplimiento de una ceremonia que marcha hacia la fijación final de la cotona? (VDOM, 21).

En algunos cuentos de Cortázar se enfrentan la visión adulta y la visión pueril, el bomo sapiens y el bomo ludens. El segundo descoloca al primero para situarlo en un plano donde sus convenciones y contextos se reorganizan como una pura ficción, como el falseamiento de una realidad más profunda que se revela, por contraste, en la esfera del juego. De la misma manera que para descubrir las posibilidades filosóficas del género fantástico, Borges define primero el relieve fantástico de toda doctrina filosófica, Cortázar reduce la realidad corriente a una ficción o juego, para descubrir en el juego los estratos más hondos de la realidad humana. Con Huizinga, acepta el carácter de juego de nuestra cultura: "mero juego de ilusiones" - dice en Rayzela-, "de reglas aceptadas y consentidas, de pura baraja en las manos de un tallador inconcebible..." $(R, 64)$. Pero estos juegos desnaturalizados aunque han perdido su carácter de tal no dejan de funcionar como juego, como documentadamente lo ha probado Eric Berne en su libro Games People Play (Juegos que la gente juega, 1964). Para Berne "la mayor parte de la actividad social del hombre consiste en jugar" y "la característica esen- 
cial del juego humano no consiste en que las emociones sean falsas, sino en que están reguladas". ${ }^{24}$ Berne se refiere a los juegos condicionados y regulados por nuestra cultura. Son juegos que han perdido casi todos los rasgos distintivos del juego y que la gente juega inconscientemente aunque constituyen, como hace notar Berne, el aspecto más importante de la vida social de cualquier complejo humano. Estos juegos han perdido lo que para Huizinga "determina la esencia del juego - la diversión o fur". Son juegos serios, que la gente juega seriamente dentro de una cultura donde la seriedad (según Caillois y Huizinga) es la medida de todas las cosas. Berne observa que la guerra sería el más trágico y absurdo de esos juegos solemnes.

En "Lejana" Cortázar confronta los dos planos del juego: el juego adulterado de los famas y el juego realizador de los cronopios. En el plano de los juegos serios nos presenta una Alina Reyes cuyo papel en "las horas de recibo de mamán" es servir el té a la señora de Regules o al chico de los Riva; en los conciertos del Odeón, hacerle compañia a su madre que juega a "ir a los conciertos"; cuando Norma canta, acompañarla al piano; con Luis María, ser su novia. Esta parte de la vida de Alina está presentada como una serie de juegos codificados por las "buenas costumbres" que Alina debe jugar porque así lo exigen los hábitos, usos y modales en los cuales se estructura su vida social. Alina los juega a pesar de ella misma: "Pobre Luis María, qué idiota casarse conmigo. No sabe lo que se echa encima. O debajo, como dice Nora que posa de emancipada intelectual" $(B, 45)$. O los juega tolerándolos, convencida de que carecen de todo sentido: "Y aguanto bien porque estoy sola entre esas gentes sin sentido..." (B, 38). O los juega a sabiendas de su resultado, en cuyo caso el juego ha perdido ese elemento de riesgo e inseguridad, generador de su placer más intenso, según anota Caillois: "Iremos allá (a Budapest)" —anota Alina en su diario. "(Luis María) estuvo tan de acuerdo que casi grito. Sentí miedo, me pareció que él entra demasiado fácilmente en este juego. $Y$ no sabe nada, es como el peoncito de dama que remata la partida sin sospecharlo. Peoncito Luis María, al lado de su reina" (B, 46). El movimiento, en efecto, acabará con el juego del noviazgo: dos meses dèspués del viaje Alina y Luis se divorcian.

Frente a estos juegos estereotipados, en los cuales Alina juega forzada por la convención, la otra Alina participa de un juego que reúne todas las características del juego tal como lo juegan los niños: como

${ }^{24}$ Etic Berne, Games People Play; The Psychology of Human Relationships. (New York, 1964), p. 18. 
actividad libre, circunscrita a ciertos límites de espacio y tiempo, incierta, sometida a una legislación diferente, acompañada de una conciencia específica de realidad segunda. Es la Alina Reyes que antes de dormirse se siente ser "una horrible campana resonando, una ola, la cadena que Rex arrastra toda la noche contra los ligustros..." (B, 35). La Alina que para dormirse repite versos, busca palabras con dos vocales y una consonante, con tres consonantes y una vocal, con las cinco vocales, $y$ construye palindromas y anagramas como éste: "Alina Reyes, es la rcina y... Tan hermoso éste, porque abre un camino, porque no concluye" $(B, 36)$. El juego ha comenzado. El único juego cuyo resultado Alina desconoce, el único que juega libremente, el único para el cual crea un espacio y un tiempo propios, el único cuyas leyes han sido estatuidas por la propia Alina, el único que conduce a una realidad donde Alina comienza a ser ella misma. Se trata de encontrar a la reina, a esa otra Alina Reyes "que tiene frío, que sufre, que le pegan". "Porque a mí" —escribe en su diario_, "a la lejana, no la quieren. Es la parte que no quieren..." $(B, 38)$. Es la parte que Alina se empeña en rescatar porque en ella ha reconocido a la otra, a la verdadera. El juego consiste en encontrarla: "ir a buscarme" - se dice Alina a sí misma. Es un ser lejano para la madre, para las señoras que toman el té en su casa, para las amigas, para el novio, pero Alina la siente tan próxima que la nieve se le mete por los zapatos y se hiela cruzando puentes helados, "en pleno Odeón". La metáfora de la lejanía de Alina, en relación a la madre y las amigas, irrumpe en el plano histórico de la narración y la Alina que sufre $y$ se hiela espera en un lejano puente de Budapest. Es una mujer harapienta y de zapatos rotos porque nada tiene, pero es ella, sin conciertos y sin tés absurdos. El juego concluye en el centro de ese puente sobre el Danubio. "En el puente la hallaré y nos miraremos" -escribe Alina en su diario en la víspera de su viaje a Budapest. "Y será la victoria de la reina sobre esa adherencia maligna, esa usurpación indebida y sorda. Se doblegará si realmente soy yo, se sumará a mi zona iluminada, más bella y cierta" (B, 47). El abrazo entre las dos mujeres es una forma de reencuentro. Cuando se separan, y Alina abre los ojos, la otra, la de los conciertos y los tés, "lindísima en su sastre gris", se aleja camino de la plaza. Ella, en cambio, es la otra, la reina de zapatos rotos.

Como en mutchos cuentos de Cortázar, también en éste realidad e irrealidad cambian de silla: el mundo del bomo sapiens se redibuja como un juego ficticio en el cual representamos el papel que nos ha sido asignado. El mundo irreal del bomo ludens, en cambio, se redefinę como 
la realidad profunda que por contraste convierte en ficción nuestra realidad corriente. El bomo sapiens juega en el ámbito de la cultura: es un juego serio que convierte al hombre en el papel que representa. El bomo ludens crea sus juegos al margen de la cultura, contra sus reglas, como una ilusión que va socavando las reglas, el tiempo y el espacio del mundo real hasta convertirlo en irrealidad. Hacia el final del cuento, la Alina Reyes real se redefine como "una adherencia maligna", como "una usur"pación indebida y sorda". En cambio la otra, la que juega a encontrar a la reina, la lejana, la que al principio nos impresiona como una ficción inventada por la Alina Reyes de los tés y los conciertos, alcanza a través del juego esa realidad que más íntima e intenșamente la define.

También en el cuento "Cartas de mamá" el juego irrumpe en la realidad segura de Laura y Luis para trastocarla en frágil engaño. La vida de Laura y Luis en París, sorprendentemente fácil, de trabajo pasable, de departamento bonito, de películas excelentes, de bosques y paseos, se redefine hacia el final del cuento como "una mentira de paz traficada", como "una felicidad de puertas para afuera". La ficción construida por Laura y Luis en París comienza a deshacerse con la primera carta donde "mamá" alude a Nico, el hermano muerto hacía dos años: "un error","una frase incomprensible y absurda", piensa Luis. Pero las cartas subsiguientes transforman el supuesto error en un juego a través del cual Laura y Luis comienzan a comprender la falsedad del otro. La vida en París se va descubriendo como un juego de gestos y posturas: las respuestas de Laura son para Luis movimientos familiares de una partida de ajedrez jugada hasta la fatiga según los mismos gambitos y contra-gambitos. Luis las registra con la certeza del jugador que ya conoce el diagrama de todos los movimientos de su adversatio: "Tenía que ser" - dice. Peón cuatro rey, peón cuatro rey. Perfecto... Ah, claro. Podria ser -dijo Laura. Caballo rey tres alfil" (AS, 24). El juego que juegan Laura y Luis en París ha dejado de ser tal porque, conocido el álgebra del juego, éste queda instantáneamente destruido. EI otro, en cambio, el que se inicia con "el error de la carta de mamá" va desplazando al primero hasta convertirse en el único juego que importa: "Luis comprendió que la partida continuaba, que a él le tocaba mover. Pero esa partida la estaban jugando tres jugadores, quizá cuatro. Ahora tenía la seguridad de que también mamá estaba al borde del tablero" (AS, 28). En esta nueva partida, la presencia de Nico se va imponiendo primero como "un territorio prohibido", como un silencio que inconfesadamente marca el ritmo de la vida de Luis y Laura en París; dẹpués, en las referencias literales de las cartas de mamá y en las 
pesadillas convulsivas de Laura; finalmente, en la realidad quemante de Nico que definitivamente los obliga a reconocer que ése es el único juego que queda por jugar, y que el de París no es más que una mentira inventada para encubrir ese pasado que "ahí queda siempre, manchando la copia en limpio, y que es (tal vez) el verdadero futuro" (AS, 8). Nico representa esa otra realidad que Laura $y$ Luis creen haber dejado en Buenos Aires $\mathrm{g}$ que termina desbaratando el juego de los cines y los bosques de París para implantar un juego en el cual se reconocen sin máscaras. Como en "Lejana", hacia el final del cuento el plano ético irnumpe en el plano histórico: Nico desborda la metáfora para entrar, mágicamente, en la realidad de Luis y Laura.

En el cuento "Final del juego", donde los personajes son niños o adolescentes, el juego posee desde el comienzo todos los rasgos de una actividad creadora y. libre. El ingreso en el espacio "irreal" del juego está descrito como el acceso a un mundo incontaminado $\mathrm{y}$ de belleza primigenia: "Abríamos despacio la puerta blanca, y al cerrarla otra vez era como un viento, una libertad que nos tomaba de las manos, de todo el cuerpo y nos lanzaba hacia adelante". Y más adelante: "... èncaramadas sobre el mundo contemplábamos silenciosas ntuestro reino" (FJ, 182). Mundo y reino definen aqui los dos planos de realidad de las tres adolescentes. El primero, el mundo, es esa realidad de platos y cacerolas, de tachos de agua sucia, de tías gritonas, de bastón de los castigos, y de esa innominada enfermedad de Leticia "en una casa (en) donde hay alguien con un defecto físico y mucho orgullo, (y) todos juegan a ignorarlo empezando por el enfermo, o más bien se hacen los que no saben que el otro sabe" (FJ, 189). En contraste con este juego de simulacros, el otro que las niñas juegan junto al talud del ferrocarril está asociado a un reino de puerta blanca, "donde reinaba una libertad absoluta" y "la mica, el cuarzo y el feldespato del granito brillaban como diamantes legítimos" (FJ, 185). En el juego, Leticia, la enferma, era "la más feliz de las tres y la más privilegiada" (FJ, 183), y al cruzar la puerta blanca dejaba "la cruz que llevaba encima" para convertirse en catidad, miedo o vergüenza (juego de las actitudes), o en una Venus o alguna princesa de un país lejano (juego de las estatuas). Leticia habita durante el juego en ese país lejano que Alina busca $\checkmark$ que.solamente encontrará en el juego: un territorio que se define en el anhelo del hombre de reconciliación con el munto y que encuentra su geografía en el juego.

El juego se acaba con la intromisión del mundo (Atiel) en el reino 
(el juego de las niñas), es decir con la ruptura de ese tiempo y espacio ideales que sostienen el juego. Como los sueños, los juegos tienen su propio ámbito de existencia. El pez, privado de agua, muere. La libertad, la sin razón del juego no toleran los códigos y la lógica razonante que gobiernan nuestra cultura. Aplicando la regla de doble crítica de los etnólogos, podtía decirse que desde esa cultura el juego es una ilusión, una irrealidad, un acontecer ficticio, como lo definen algunos de sus estudiosos; pero desde la realidad del juego, nuestra realidad histórica se redefine como un falso juego en que el bomo sapiens, "después de habetlo esperado todo de la inteligencia y del espíritu, se encuentra como traicionado, oscuramente consciente de que sus armas se han vuelto contra él, que la cultura, la civiltà, lo han traído a este callejón sin salida donde la barbarie de la ciencia no es más que una reacción comprensible" ( $R$, 506-507). El bomo ludens, ser irracional por excelencia, busca en el juego un reino perdido, un puente hacia ese ser que somos pero del cual nos separan los gestos, las conductas intachables y los altos conceptos, un tiempo libre de precisiones y simetrías, una seriedad que no deshecha el humor y la alegría. En los cuentos estudiados el juego aparece como una liberación, como la reconquista de una libertad generada no por las necesidades de un conglomerado social (los conciertos y los tés en "Lejana", el París fácil de "Cartas de mamá") sino por esas necesidades o fuerzas ("ciegas" para la razón) que nos compelen a rescatar a la mendiga de zapatos rotos o a aceptar vivo al Nico que dábamos por muerto. El juego, entonces, lejos de ser una ficción, una irrealidad, un espacio y un tiempo inexistentes, como normativamente se lo define, es un intento de inversión de papeles: abandonamos el que prolija y solemnemente representamos en el juego del bomo sapiens para asumir un juego desde el cual el bomo ludens "no es sino que busca ser" $(R, 418)$. En las notas de Morelli se habla de un libro en el cual "las conductas standard serían inexplicables con el instrumental psicológico al uso. Los actores parecerían insanos o totalmente idiotas... En ellos algo que el bomo sapiens guarda en lo subliminal se abriría penosamente un camino como si un tercer ojo parpadeara penosamente debajo del hueso frontal. Todo sería como una inquietud, un desasosiego, un desarraigo continuo, un territorio donde la causalidad psicológica cedería desconcertada, y esos fantoches se destrozarían o se amarían o se reconocerían sin sospechar demasiado que la vida trata de cambiar la clave en y a. través y por ellos, que una tentativa apenas concebible nace en el hombre como en otro tiempo fueron naciendo la clave-razón, la clave-sentimiento, la clave-pragmatismo" ( $R, 417)$. El 
juego sería una de estas claves. Los tres cuentos aludidos se proyectan, así, como tentativas o manifestaciones de una clave que encuentra en el juego su vehículo expresivo.

University of Californit, San Diego.

JAIME ALAZRAKI 